\title{
Papers
}

\section{Outcomes of screening to prevent cancer: analysis of cumulative incidence of cervical abnormality and modelling of cases and deaths prevented}

\author{
A E Raffle, B Alden, M Quinn, P J Babb, M T Brett
}

\begin{abstract}
Objective To determine the frequency of different outcomes in women participating in cervical screening.

Design Analysis of screening records from 348419 women, and modelling of cases of cervical cancer and deaths with and without screening.

Setting Cervical screening programme in Bristol.

Results For every 10000 women screened from 1976 to 1996,1564 had abnormal cytology, 818 were investigated, and 543 had abnormal histology. One hundred and seventy six had persistent abnormality for two years or more. In the absence of screening 80 women would be expected to develop cancer of the cervix by 2011 , of whom 25 would die. With screening 10 of these deaths would be avoided. Comparison of cumulative abnormality rates with numbers expected to develop cancer in the absence of screening suggests that at least $80 \%$ of high grade dyskaryosis and of high grade dysplasia would not progress to cancer. The lifetime risk of having abnormal cytology detected could be as high as $40 \%$ for women born since 1960.

Conclusions Screening is labour and resource intensive. It involves treatment for many women not destined to develop invasive cancer. The increased intervention rate for cervical abnormality in England is due to change in practice, not a cohort effect, and is probably the reason for the marked fall in incidence and mortality during the 1990s. For other cancers there is scope for major iatrogenic harm from screening because of invasive tests and treatments.
\end{abstract}

\section{Introduction}

Cervical screening inevitably detects abnormalities that will never progress to life threatening disease. This creates alarm for healthy women and dilemmas for clinicians advising them. By the late 1990s the cervical screening programme was responsible for averting an estimated 800 deaths annually in women under 55 years in England ${ }^{2}$ or 1300 deaths in all women in England and Wales. ${ }^{3}$

Recognition that benefit for some comes at the price of harm for others has prompted considerable debate about the information women need for understanding what screening offers. ${ }^{4-7}$ National guidance confirms that the purpose of information about screening is to ensure that participants can make a fully informed choice. ${ }^{8}$ Nevertheless, public belief and the perceptions of journalists, politicians, lawyers, and many health professionals still reflect 30 years of simplistic messages used to encourage attendance for screening. ${ }^{40-12}$

Accurate information about the consequences of screening is needed to assist participating individuals and to inform policy on preventive strategies nationally and internationally. Such data have not previously been published for cervical screening. We used records from a cytology database and cancer registration and mortality data to derive information about outcomes.

\section{Methods}

Cervical screening in the Bristol area (corresponding now to four primary care trusts) began in 1966. In April 1996, 244535 women aged 20 to 64 years were registered with Bristol and District general practitioners. During the period covered by this analysis, all contemporary national guidance was complied with and reporting ranges for abnormal results were within national recommended ranges. Women were invited for testing every five years from the age of 24.

The Avon cytology database holds records for all women with smears processed by the two screening laboratories and by private laboratories in Bristol from 1976. Careful record matching has ensured there are no duplicate or fragmented records on the database. Up to 31 March 1996 the database contained test results for 351331 women. We excluded data on 498 women with unknown date of birth and on 2414 born before 1911 because they were older than the recommended age for screening in 1976. This left 348419 records for inclusion in the study.

\section{Cumulative incidence analysis}

We performed analyses separately for each five year birth cohort. Combination of these results gives an "average" experience across all ages and cohorts during the 20 years of calendar time; those for a single cohort give more specific information, but for less than half of the screening age span.
Avon Health Authority, King Square House, Bristol BS2 8EE A E Raffle consultant in public health medicine

B Alden systems analyst

National Cancer Intelligence Centre Office for National Statistics, London SW1V 2QQ

M Quinn director

P J Babb

senior cancer epidemiologist

Department of Cellular Pathology, Southmead Hospital, Bristol BS10 5NB

MT Brett consultant pathologist

Correspondence to: A E Raffle angela.raffle@ bristolnorth-pct. nhs.uk

bmj.com 2003;326:901 
Large numbers of women leave and join any cervical screening database because of age, change of address, change of general practitioner, and decisions about whether or not to be screened. We analysed incidence rates during the 20 years by looking at five year periods and for each period used the total number of women having tests during that five years as the denominator. We used the full past record for each woman, up to the end of the five years in question, to determine the first and worst occurrences of abnormal smear test and biopsy results. A new occurrence of abnormality was defined as the first occurrence of the worst grade in a woman's record, taking her entire record from April 1976 up to the end of the five year period under analysis. Table 1 shows the descending hierarchy for classifying worst. The cytology categories correspond to the national cervical smear report form (HMR101). Borderline change has been used as a result category by the Bristol laboratories since 1981 . Mild dyskaryosis has been coded separately from moderate since June 1990 and subsequent data show that $39 \%$ of women in the combined "mild and moderate" category had had at least one test result recorded as moderate dyskaryosis. Adenocarcinoma of the cervix was lower in the hierarchy than cervical intraepithelial neoplasia because the programme primarily detects squamous abnormalities.

To ascertain the frequency of persisting abnormality detected at screening we analysed the length of time between first and last abnormal result for every woman for the full 20 years. The total number with results in the 20 years was the denominator for expressing these data as rates.

\section{Modelling of expected cases and deaths}

Numbers of cases and deaths if screening had not taken place We estimated the numbers of cases and of deaths from cancer of the cervix that would have occurred in the absence of screening in the study population up to 1996 and projected the estimate for a further 15 years to 2011. To do this we applied adjusted age specific

Table 1 Numbers and rates of women with abnormal cytology* and abnormal histology* per 100 women tested since 1976 for those screened in 1991-6

\begin{tabular}{|c|c|c|c|c|}
\hline & \multicolumn{2}{|c|}{ All women } & \multicolumn{2}{|c|}{$1956-60$ births } \\
\hline & $\begin{array}{c}\text { No of } \\
\text { women }\end{array}$ & $\begin{array}{c}\text { Rate/1000 } \\
\text { tested }\end{array}$ & $\begin{array}{c}\text { No of } \\
\text { women }\end{array}$ & $\begin{array}{c}\text { Rate/1000 } \\
\text { tested }\end{array}$ \\
\hline \multicolumn{5}{|l|}{ Abnormal cytology: } \\
\hline Severe dyskaryosis & 6497 & 30.3 & 1250 & 44.9 \\
\hline Moderate and mild dyskaryosis & 12778 & 59.5 & 1863 & 66.9 \\
\hline ?Glandular neoplasia & 401 & 1.9 & 39 & 1.4 \\
\hline Borderline changes & 13876 & 64.7 & 1762 & 63.3 \\
\hline Total abnormal cytology & 33552 & 156.4 & 4914 & 176.4 \\
\hline Total with biopsy recorded & 17558 & 81.8 & 2733 & 98.1 \\
\hline \multicolumn{5}{|l|}{ Abnormal histology: } \\
\hline Invasive squamous cancer & 259 & 1.2 & 38 & 1.4 \\
\hline Microinvasive squamous cancer & 214 & 1.0 & 32 & 1.1 \\
\hline CIN grade III & 4885 & 22.8 & 989 & 35.5 \\
\hline CIN grade II & 2863 & 13.3 & 495 & 17.8 \\
\hline CIN grade I & 1527 & 7.1 & 237 & 8.5 \\
\hline Adenocarcinoma endocervix & 37 & 0.2 & 9 & 0.3 \\
\hline Borderline atypia, wart virus, GIN & 1871 & 8.7 & 263 & 9.4 \\
\hline Total abnormal histology & 11656 & 54.3 & 2063 & 74.1 \\
\hline Total tested & 214582 & & 27854 & \\
\hline
\end{tabular}

$\mathrm{CIN}=$ cervical intraepithelial neoplasia; GIN=glandular intraepithelial neoplasia.

*Only first and worst occurrence of abnormal cytology and first and worst occurrence of abnormal histology are counted. incidence and death rates for England and Wales to the cumulative numbers tested within each birth cohort and each five year period. The adjusted rates assumed that without screening incidence and mortality would have followed the age specific pattern exhibited by the pre-1930s birth cohorts in England and Wales (in whom there is no evidence of a screening effect) and that the absolute risk would have risen in cohorts of women born since 1950. Evidence for this increase in risk in cohorts after the 1950 s comes from national cancer registration and mortality data, ${ }^{13}$ serological prevalence data relating to high risk exposure to human papilloma virus, ${ }^{14}$ and age specific first detection rates for severe dyskaryosis. ${ }^{1}$

We carried the projections forward to 2011 because abnormality detected at screening theoretically predates invasive cancer by up to 15 years. The cumulative total tested in each cohort was used for the forward projections and as the denominator for converting numbers to rates. By assuming that the recent downturn in deaths is entirely a screening effect, and that lifetime risk is higher in women born since 1950, we ensured that we did not underestimate the benefit of screening. We then compared these estimates with the incidence of abnormality detected at screening.

\section{Numbers of cases and deaths with screening}

We estimated the numbers of cases and deaths with screening in the study population by applying unadjusted incidence and mortality for England and Wales by age and by birth cohort to the cumulative numbers tested within each birth cohort and each five year period. Because all cohorts nationally are now well screened there are few data on which to model incidence predictions beyond $1996 .{ }^{13}$ For our study population we predicted deaths with screening by assuming that after 1996, $60 \%$ of the modelled deaths without screening are averted. This is based on the finding that in 1997 over $60 \%$ of deaths from cervical cancer in women under 55 seemed to be prevented by screening. ${ }^{3}$ It is highly unlikely that detection and treatment of cervical abnormalities during 1976-96 in our study population could have yielded greater benefit than this estimate.

\section{Results}

The numbers of women tested rose markedly during the first three five year periods from 109000 to 232000 and fell by around 7\% to 215000 in the fourth period, although population uptake was maintained at $87 \%$.

\section{Cumulative incidence}

Among the 214582 women with an adequate test during 1991-6, 33552 (15.6\%) had abnormal cytology, $17558(8.2 \%)$ had a record of biopsy, and 11656 (5.4\%) had abnormal histology detected at any time during the 20 years of the study (table 1). In addition, 26818 women $(7.7 \%$ of the total) had no abnormal results but required an early repeat test because one or more smears were inadequate for examination.

The most comprehensive data were those for women born 1956-60. Among these women 4914 (17.6\%) had abnormal cytology, 2733 (9.8\%) had a 
record of biopsy, and 2063 (7.4\%) had abnormal histology (table 1) at any time during the 20 years of the study.

Persistent or recurrent abnormality over a period of more than two years occurred in 6130 women $(1.8 \%$ of all tested), and 1845 (0.5\%) had abnormal results for over five years. There was a steep increase in detection rates over time (fig 1). For example, in women aged 40 (on average) the rate for those born in 1946-51 (tested 1986-91) was almost six times higher than for those born in 1936-41 (tested during 1976-81). These two cohorts would not be expected to have such major differences in lifetime risk. Change in the risk profile of women attending screening and removal of lesions by treatment cannot explain the difference. This leaves reversal of abnormal cytology and changed diagnostic thresholds as the major explanations. Diagnostic criteria for severe dyskaryosis remained relatively stable. ${ }^{1}$ The corresponding difference in rates of severe dyskaryosis alone was more than fourfold.

\section{Modelling of expected cases and deaths}

The modelling predicts that without screening and for all women in the study population 2774 (7.96 per $1000)$ would have developed invasive cervical cancer by 2011,878 (2.52 per 1000) of whom would have died from it (table 2). For women born in 1956-60 in the absence of screening 538 (11.76 per 1000) would have developed invasive cervical cancer by 2011, of whom 127 (2.78 per 1000) would have died from it.

By 1996 the modelling predicts that 192 fewer cases and 27 fewer deaths would have occurred in the study population as a result of screening, assuming that reductions seen nationally in incidence and mortality apply equally in Bristol (table 2). Table 2 also shows cumulative numbers of deaths from cervical cancer in the study population if $60 \%$ of deaths after 1996 are averted because of screening. An estimated 357 deaths will have been prevented by 2011 .

\section{Combined consequences, benefits, and harms}

For each 10000 women screened from 1976 to 1996, 1564 had abnormal cytology, with 554 of these being high grade (moderate dyskaryosis or worse and query glandular neoplasia); 769 underwent repeat testing because of inadequate smears but with no abnormality;

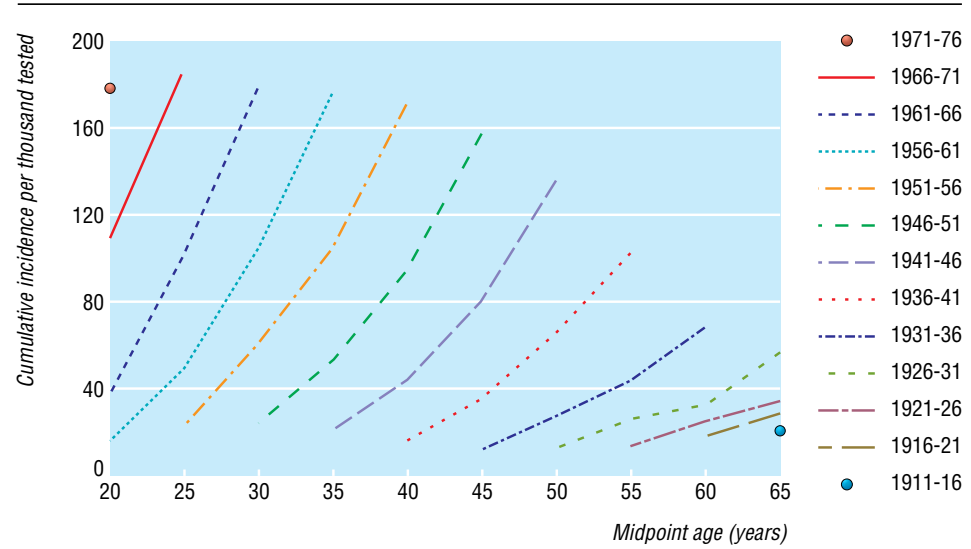

Fig 1 Cumulative incidence by birth cohort (April 1911 to March 1976, in five year age groups) for detection of abnormal cytology, all grades combined, 1976-96

818 underwent biopsy (385 had high grade abnormality or worse (invasive or microinvasive squamous carcinoma, cervical intraepithelial neoplasia grade II, cervical intraepithelial neoplasia grade III, adenocarcinoma), 158 had low grade abnormality); and 176 had persistent abnormal results over more than two years (fig 2). Without screening an estimated 80 women would have developed cervical cancer by 2011 of whom 25 would die. According to the modelling, screening of 10000 women during this 20 years and a further 15 years beyond would prevent 10 of the 25 deaths.

From these data 13000 (348419/27) women needed to be screened over 20 years to prevent one death up to 1996, which would represent around 57000 tests $((13000 \times 4)$ plus $10 \%$ for repeats $)$. For each death prevented 1955 women had abnormal cytology (1564/0.8), of whom 1023 had biopsy. Incorporating future estimates of $60 \%$ mortality reduction from 1996 gives $1000(348$ 419/357) as the number of women needing to be screened for 35 years to prevent one death, involving some 7700 tests $((1000 \times 7)$ plus $10 \%$ for repeats). The ratio of abnormal results to deaths prevented cannot be determined because the cumulative incidence up to 2011 is not yet known.

Table 2 Estimated cumulative numbers of women in study population expected to develop, or die from, invasive cervical cancer during each test period and for further 15 years into future, without screening (adjusted rates) and with screening (unadjusted rates). Expected deaths with screening beyond 1996 assume 60\% of deaths after 1996 are prevented by screening

\begin{tabular}{|c|c|c|c|c|c|c|c|}
\hline & 1976-81 & $1981-86$ & 1986-91 & 1991-6 & 1996-2001 & 2001-6 & 2006-11 \\
\hline \multicolumn{8}{|l|}{ All women } \\
\hline No at risk (cumulative total tested) & 109012 & 204327 & 287300 & 348419 & 348419 & 348419 & 348419 \\
\hline \multicolumn{8}{|l|}{ Cases: } \\
\hline Without screening & 85 & 271 & 594 & 1038 & 1527 & 2130 & 2774 \\
\hline With screening & 85 & 271 & 594 & 846 & - & - & - \\
\hline \multicolumn{8}{|l|}{ Deaths: } \\
\hline Without screening & 32 & 95 & 194 & 327 & 490 & 673 & 878 \\
\hline With screening & 32 & 95 & 194 & 300 & 365 & 439 & 521 \\
\hline \multicolumn{8}{|l|}{ 1956-60 births } \\
\hline No at risk (cumulative total tested) & 15478 & 30608 & 40694 & 45737 & 45737 & 45737 & 45737 \\
\hline \multicolumn{8}{|l|}{ Cases: } \\
\hline Without screening & 2 & 23 & 76 & 173 & 249 & 371 & 538 \\
\hline With screening & 2 & 23 & 76 & 118 & - & - & - \\
\hline \multicolumn{8}{|l|}{ Deaths: } \\
\hline Without screening & 0 & 4 & 13 & 29 & 55 & 86 & 127 \\
\hline With screening & 0 & 5 & 13 & 24 & 35 & 47 & 64 \\
\hline
\end{tabular}




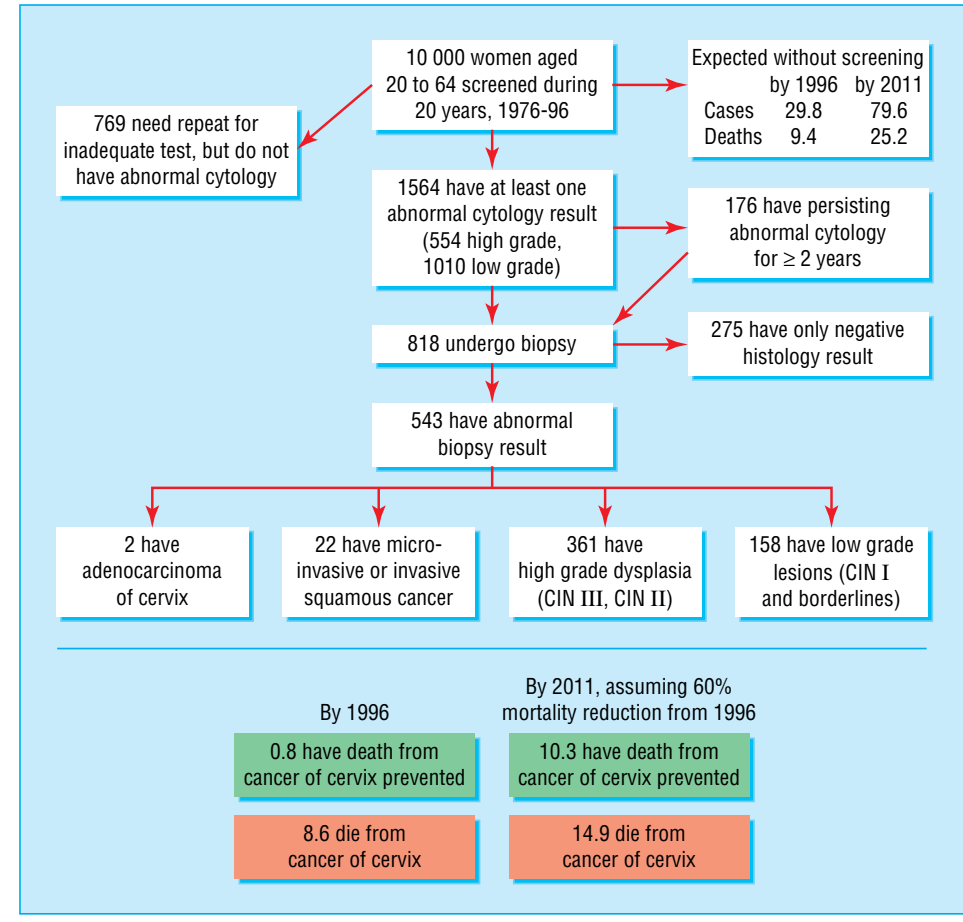

Fig 2 Outcomes per 10000 women for cervical screening in study population, 1976-96, and for modelling of cervical cancer cases and deaths up to 2011

\section{Progression rates}

By 2011, we estimate that without screening 80 per 10000 women would have developed invasive cancer. The rate of progression to cancer for high grade cytological abnormality (detected in 554 per 10000 ) cannot therefore be greater than $14.4 \%(80 / 554 \times$ $100)$ as some cancers will arise in women whose worst ever recorded result was mild, borderline, or negative. For histological abnormality, 22 per 10000 had invasive or microinvasive squamous cancer on biopsy and two had adenocarcinoma, which leaves 56 of the estimated 80 cancers per thousand to arise from 228 cases of cervical intraepithelial neoplasia grade III and 133 cases of cervical intraepithelial neoplasia grade II (see table 1). The progression rate for grade II and III combined can therefore be no greater than $15.4 \%$ (56/ $361 \times 100)$

\section{Discussion}

If we assume that mortality from cervical cancer has decreased by $60 \%$ since 1996 , then 1000 women have had to be screened for 35 years to prevent one death. Put in context, a nurse performing 200 tests each year-the workload for two general practitioners' lists-would prevent a death once in 38 years $(7700 / 200)$. During this time she or he would care for over 152 women with abnormal results (1564/10.3), over 79 women would be referred for investigation, over 53 would have abnormal biopsy results, and over 17 would have persisting abnormalities for more than two years. At least one woman during the 38 years would die from cervical cancer despite being screened.

Many attempts have been made to estimate regression, persistence, and progression rates for different grades of abnormality. ${ }^{15-18}$ Our comparison of the expected number of cancers by 2011 with the number detected up to 1996 suggests that at least $80 \%$ of women with high grade lesions will not develop invasive cancer. Lower ascertainment of cervical intraepithelial neoplasia may explain the higher progression rates estimated in previous studies.

Since 1987 deaths from cervical cancer in Bristol have fallen in line with national figures (Office for National Statistics, VS3). Hence high coverage and good quality control in the 1970 s and 1980s did not result in a significant change in death rates in Bristol before the national changes to the screening programme. This suggests that the reduction in mortality resulted from widening definitions for categorising abnormality ${ }^{19}$ and the consequent increase in numbers treated. Cytological screening may be so non-specific that it is possible to prevent fatal cancers only by treating large numbers of women.

Our results are likely to apply to other comprehensive and quality assured cervical screening programmes. When screening is more frequent than five yearly there may be more women with abnormal results for each death prevented. In populations with a higher incidence of cervical cancer one would expect fewer women to be labelled and treated for each death prevented.

\section{Implications}

These findings have important implications. First is the scale of the problem of overdetection. Even women who receive results of borderline changes can become anxious about their risk of cancer. ${ }^{20}$ Figure 1 shows that for younger cohorts the cumulative lifetime incidence for any abnormality could reach $30-40 \%$. It is essential therefore that we change people's perception of the meaning of an abnormal screening result.

Secondly, because of the resources involved and the potential to do harm, it is in the public's interest to

\section{What is already known on this topic}

Since the mid-1980s incidence of and mortality from cervical cancer in women born since the 1930s in England and Wales has fallen; screening is the most likely explanation

For each death prevented many women have to be screened and many are treated who would not have developed a problem

\section{What this study adds}

In the NHS cervical screening programme around 1000 women need to be screened for 35 years to prevent one death

Over $80 \%$ of women with high grade cervical intraepithelial neoplasia will not develop invasive cancer, but all need to be treated

For each death prevented, over 150 women have an abnormal result, over 80 are referred for investigation, and over 50 have treatment

Before the 1988 relaunch of screening with strict quality standards, for each death prevented there were 57000 tests and 1955 women had abnormal results 
control the introduction of inadequately evaluated or of inadequately quality assured cancer screening. Our results show that cervical screening in England and Wales before 1996 entailed 57000 tests and 1955 abnormal results for each death prevented. Prostate specific antigen testing for early detection of prostate cancer will involve similarly large numbers of tests and abnormal results and the net result will be major iatrogenic harm from invasive investigations and treatments. We have a duty to protect the public from this damaging activity until there is good evidence on all outcomes.

Finally, our results suggest that over $80 \%$ of high grade dyskaryosis and of high grade dysplasia in the cervix does not progress to invasive cancer. This calls into question the prophylactic removal of other organs (colon, ovaries, breast, oesophagus) and the offer of potentially harmful chemotherapy and radiotherapy treatments for healthy people found to have dysplasia of those organs. The net result could be harm because the absolute risk of progression in these tissues may be low.

We thank David Prothero for advice with the cumulative incidence analysis, Caroline Joy for assistance with database queries, and Elizabeth Mackenzie for establishing the Avon cytology database.

Contributors: AER is guarantor and designed the study with help from MTB and MQ. BA performed the programming to analyse the cytology and histology records. PJB carried out the statistical modelling with advice from MQ and AER. AER drafted the paper, with editorial assistance from MQ. All authors approved the final version.

Funding: BA received funding from NHS Research and Development Directorate. The guarantor accepts full responsibility for the conduct of the study, had access to the data, and controlled the decision to publish.

Competing interests: None declared.
1 Raffle AE, Alden B, Mackenzie EF. Detection rates for abnormal cervical smears: what are we screening for? Lancet 1995;345:1469-73.

2 Quinn M, Babb P, Jones J, Allen E. Effect of screening on incidence of and mortality from cancer of cervix in England: evaluation based on routinely collected statistics. BMJ 1999;318:904-8.

3 Sasieni P, Adams J. Effect of screening on cervical cancer mortality in England and Wales: analysis of trends with an age period cohort model. BMJ 1999;318:1244-5.

4 Anderson CM, Nottingham J. Bridging the knowledge gap and communicating uncertainties for informed consent in cervical cytology screening: we need unbiased information and a culture change. Cytopathology 1999;10:221-8.

5 Raffle AE. Information about screening-is it to achieve high uptake or to ensure informed choice? Health Expect 2001;4:92-8.

6 Slater DN. Are women sufficiently well informed to provide valid consent for the cervical smear test? Cytopathology 2000;11:166-70.

7 Foster P, Anderson CM. Reaching targets in the national cervical screening programme: are current practices unethical? J Med Ethics 1998;24:151-7.

8 General Medical Council. Seeking patients' consent:the ethical considerations. London: General Medical Council, 1998.

9 UK National Screening Committee. Second report. London: Departments of Health for England, Scotland, Northern Ireland, and Wales, 2000.

10 Frable WJ, Austin RM, Greening SE, Collins RJ, Hillman RL, Kobler TP, et al. Medicolegal affairs. International Academy of Cytology Task Force summary. Diagnostic cytology towards the 21st century: an international expert conference and tutorial. Acta Cytol 1998;42:76-119.

11 Raffle AE. How long will screening myths survive? [letter]. Lancet Raffle AE. How

12 Slater D. The cervical screening muddle. Lancet 1998;351:1130.

13 Quinn M, Babb P, Brock A, Kirby L, Jones J. Cancer trends in England and Wales. London: Office for National Statistics, 2001.

14 Dillner J. Trends over time in the incidence of cervical neoplasia in comparison to trends over time in human papillomavirus infection. J Clin Virol 2000;19:7-23.

15 Bos $\mathrm{AB}$, van Ballegooijen $\mathrm{M}$, van Oortmarssen GJ, van Marle ME, Habbema JD, Lynge E. Non-progression of cervical intraepithelial neoplasia estimated from population-screening data. Br J Cancer neoplasia estim

16 Ostor AG. Natural history of cervical intraepithelial neoplasia: a critical review. Int J Gynecol Pathol 1993;12:186-92.

17 Furber SE, Weisberg E, Simpson JM. Progression and regression of lowgrade epithelial abnormalities of the cervix. Aust N Z J Obstet Gynaecol 1997;37:107-12.

18 Holowaty P, Miller AB, Rohan T, To T. Natural history of dysplasia of the uterine cervix. J Natl Cancer Inst 1999;91:252-8.

19 Evans DMD, Hudson EA, Brown CL, Baddington, MM, Hughes HE, Mackenzie EF, et al. Terminology in gynaecological cytopathology: report of the working party of the British Society for Clinical Cytology. J Clin Pathol 1986;39:933-44

20 Marteau TM, Walker P, Giles J, Smail M. Anxieties in women undergoing colposcopy. Br J Obstet Gynaecol 1990;97:859-61.

(Accepted 27 February 2003) 